of thought and condensation of the results are very important, and I consider Laplace's universal formula as a legitimate ideal. There is no question that the Hamiltonian principls is the adequate formulation of this tendency. It would be the universal formula if only the correct expressions for the potential energy of all forces were known. Nineteenth century thinkers believed more or less explicitly in this programme, and it was successful in an amazing degree.

By choosing a proper expression for the potential energy, nearly all phenomena could be described, including not only the dynamics of rigid and elastic bodies, but also that of fluids and gases, as well as electricity and magnetism, together with electronics and optics. The culmination of this development was Einstein's theory of relativity, by which the abstract principle of action regained a simple geometrical interpretation. The motions of the planets can be considered as 'geodesics' in the four-dimensional space formed by adding time to our common space. Einstein's law of gravitation, which contains Newton's law as a limiting case, can also be derived from an extremum principle in which the quantity that is an extremum can be interpreted as the total curvature of the space-time world.

We call this period of physics which ends with the theory of relativity the classical period, in contrast to the recent period which is dominated by quantum theory. The new quantum mechanics assumes that all laws of physics are of statistical character. The fundamental quantity is a wave function which obeys laws similar to those of an acoustical or optical wave; it is not, however, an observable quantity, but determines indirectly the probability of observable processes. The point which interests us here is the fact that even this abstract wave function of quantum mechanics satisfies an extremum principle of the Hamiltonian type.

We are still far from knowing Laplace's universal formula, but we may be convinced that it will have the form of an extremal principle, not because Nature has a will or purpose or economy, but because the mechanism of our thinking has no other way of condensing a complicated structure of laws into a short expression.

\title{
Science at the Golden Gate Exposition
}

\section{By Science Service, Washington, D.C.}

\begin{abstract}
A SUPER-SPECTACLE of science at work is unfolded at the Golden Gate International Exposition, the World's Fair of the West, at San Francisco, which was opened on February 19. Treasure Island itself is an engineering triumph, for it is entirely a man-made island in San Francisco Bay, 400 acres in area. After the close of the fair, the buildings will be razed and the island will become the San Francisco-Bay Area airport; already Pan-American Airways clippers to the Orient use the island as the home port. From the hunt for subatomic particle of tiniest size to wondering about the course of a distant star, from war on death-dealing virus too small to be seen under an ordinary microscope to giant engineering projects like man-made Treasure Island itself, science dominates the $50,000,000$ dollar show.

Only one hall bears the identifying label, "Hall of Science", but the entire exposition is as much a demonstration of the research worker's genius and accomplishments as this single building. Student of biology or of physics, layman or lover of the spectacular-all will find what they want in this twentieth-century panorama. Rats are thriving on synthetic food, insect friend of man battles insect foe, two liquids become artificial rubber, a machine
\end{abstract}

talks in words that never issued from a human throat-all this happens and much more during the 288 days the fair will be open.

The keynote of the entire science display is an exhibit which cost a quarter of a million dollars, prepared by the University of California. Among the exhibits of particular scientific interest are the following. (a) 'Test tube' plants, grown by scientific workers of the Plant Nutrition Division of the University of California in a demonstration of the most significant contribution of agricultural science to modern farming-'soilless farming'. Just as Pan-American Airways is doing on tiny Wake Island to supply fresh vegetables to clipper passengers and crews and as California planters are now learning, tomatoes and other truck products are grown in water containing nourishing chemicals instead of in soil. Spectators will see for themselves the tremendous yields made possible by this method. (b) Californian men of science show in a specially constructed chamber just how harmful noise can be to the human organism, and what can be done about it. (c) No playthings are a set of dolls which are displayed. They teach the curious thousands how mother and father pass on their characteristics to their 


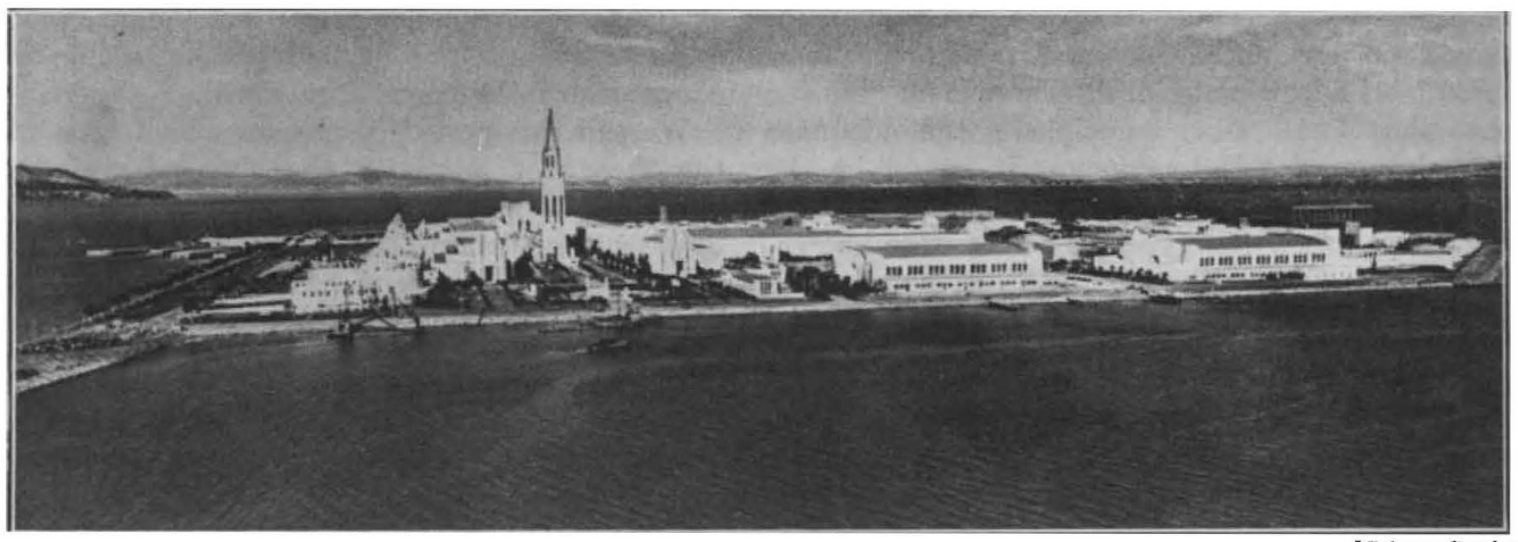

[Science Service

Fig. 1. A general view of Treasure Istand, site of the Golden Gate International Exposition, AND THE EXPOSITION BUILDINGS.

children. Colour of eyes is the specific characteristic traced in the set of exhibition mannequins. (d) The University of California, where Prof. Ernest O. Lawrence, of cyclotron fame, is a faculty member, is a world centre of research into the secrets of the atom. So it is to be expected that a model of the world's and California's greatest cyclotron should be there.

California's biggest academic institution, however, is not the only science exhibitor. PanAmerican Airways is staging a great aviation show by demonstrating the operation of the clippers that fly to China and the Philippines. Small boys face plenty of competition from their elders for space behind the glass partition in Pan-American Airways' great new hangar. On the other side, 'grease monkeys' and members of crew and passengers go about their business. Treasure Island has become the new San Francisco base for the airline that flies the Pacific, and all operations will be visible for the duration of the Fair. After December 2, closing day, and after the exhibit buildings have been removed, other airlines will transfer their headquarters from Oakland Airport and Mills Field on the San Francisco side of the bay to this single skyport.

Riches of the earth and the miner's art are shown in a synthetic mountain, Treasure
Mountain, which visitors enter through a 'valley' between two 'mountain ranges'. Every type of mining operation on different key ores of the mineral-laden West is shown in working form-a 2,500-miles science trip in a few minutes. The peak is $50 \mathrm{ft}$. high and $400 \mathrm{ft}$. long.

Anthropologists and archæologists will find assembled unbelievably old treasures, dating back to earliest times, from the countries bordering the Pacific. Stone axe heads forty-nine centuries old from Siam, and gorgeous specimens of the goldsmith's art in the Chimu culture that preceded Peru's highly civilized Incas of four hundred years ago, that have added to man's store of knowledge concerning himself, are shown on Treasure Island.

The Federal exhibit, which cost one and a half million dollars, shows activities of the National

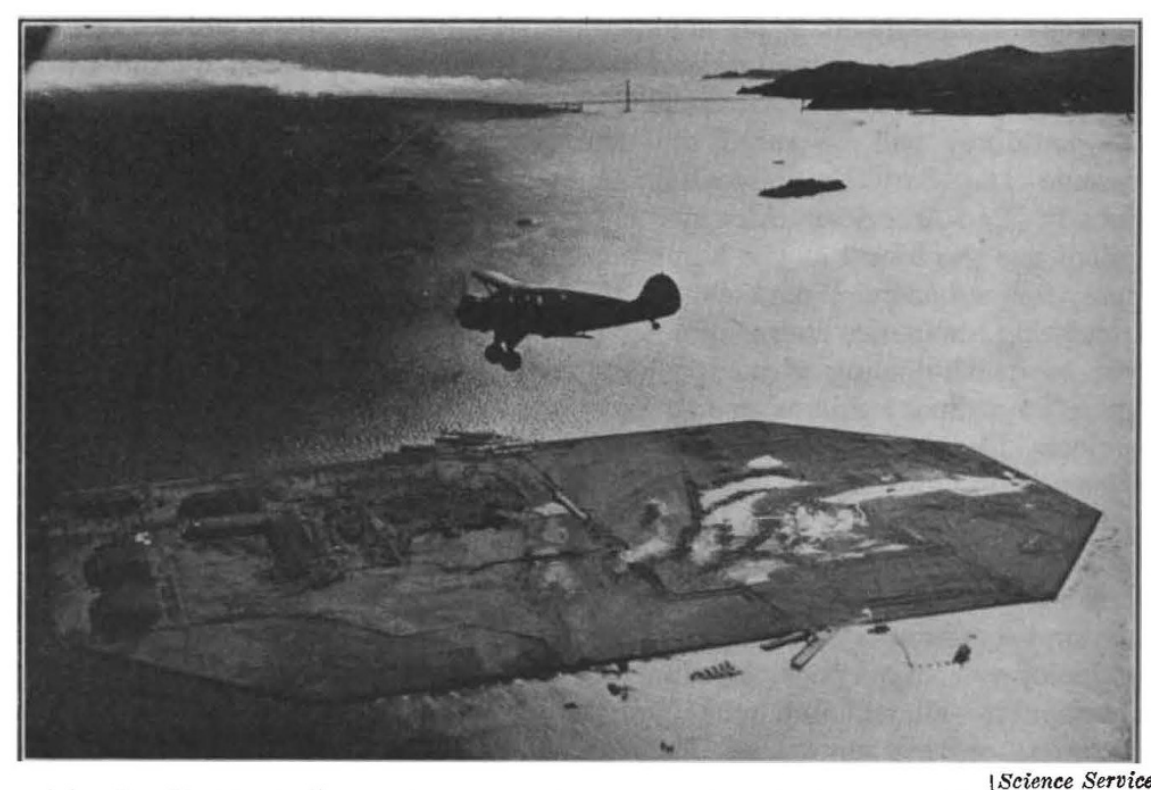

Fig. 2. Treasure Island JUSt before buildings, trees, Shrubs and FLOWERS AND EXHIBITS BEGAN TO BE MOVED ON TO THE ISLAND. 
Government, as they affect citizens, around seven central themes. One, for example, displays in dramatic form what Uncle Sam does for Mr. Average Man from birth through old age-how, for example, Public Health Service grants provide better maternity care and how the Social Security Board now provides for a man in his declining years.

Indians demonstrate their handicrafts in the Federal building. Not only do they show their unique art, but also they may start a vogue for Indian handicrafts among visitors. Planners of the exhibit certainly hope so, for such a boom would prove a boon to the Rəd man, who has not had an easy row to hoe in adapting himself to the white man's civilization.

Chemical wizardry, as practised by industrial giants whose ever-new products enter into everyone's life every day, are also shown. The Dow Chemical Company shows how it makes ocean water yield up magnesium, the lightest metal now in use, and iodine and bromine, two vital chemicals which enter into, among other things, the old stand-by antiseptic and photographic film respectively.

A chemist pours the clear contents of one beaker into another and a gummy substance, which is then moulded into proper shape, results. It is allowed to solidify, and, lo! a rubber tyre. How chemistry makes for better living in this and in other ways is shown by E. I. du Pont de Nemours and Co.

An 'iron lung', about which much has been heard recently and which has saved many lives, is there. Visitors have a chance to watch one at work in a model hospital erected by Dr. Gabriel Barnett.

In charge of the vast science programme in the Hall of Science alone has been Dr. Milton Silverman. Co-operating with him as exhibitors he has had some of the foremost scientific institutions in the United States. Harvard University, the Mayo Clinic, the Jackson Clinic and the American Medical Association, to mention only a few, are taking part. More than two hundred and fifty industrial exhibits, of which many are science shows all by themselves, are represented.

\section{Technical Education in Great Britain}

$\mathrm{A}^{\mathrm{s}}$ $\mathrm{S}$ was to be expected, the principal discussion at the annual meeting, held in London on February 24-25, of the Association of Technical Institutions, centred around the recommendations with regard to technical education put forward in the Spens Report. Sir Henry Steward, chairman of the City and Guilds of London Institute, who has succeeded Sir Robert Pickard as chairman of the Association, presided over the meetings, which were held in the Hall of the Merchant Taylors Company.

The discussion was opened by Principal J. Paley Yorke, one of the signatories to the Report, and chairman of the Council of the Association. He said that the general trend of the Report has been aptly expressed by one commentator as "a shifting of the basis of education from one of social habit to one of natural aptitude". Who should say that a parent should not take account of the social implications which attach themselves to a child by attendance at one school or another ? But if some equality of status can be secured between schools of different educational types the parent will no longer find himself forced to weigh social esteem against educational provision. $\mathrm{He}$ need only think of the fitness of the curriculum for the aptitude and the inclinations of the child. The text of the Report on the inside title-page is "Chacun doit être à portée de recevoir l'éducation qui lui est propre." The recommendations endeavour to make that possible.
Mr. Paley Yorke then went on to describe and explain the findings of the Committee set out in Chapter viii--"Technical High Schools and other Technical Schools". He pointed out that the terms of reference made it necessary for the Committee to give a detailed consideration of the aims, objects and work of those schools called Junior Technical Schools and to determine their actual and potential relation to secondary schools of other types. This is the first time in history that so complete an examination has been made by so important a Committee. The members of the Committee found it necessary to collect a large body of evidence, and they visited a number of representative schools to obtain for themselves a true picture of their work, of the staffing, equipment and corporate life. The Committee was greatly impressed through these visits and was the better able to assess the oral and written evidence received. It recognized that there are two main groups of Junior Technical Schools in existence-one frankly and definitely preparing its pupils for entry into a specific occupation and developing in them a substantial measure of personal skill in the processes of that occupation-the other providing an educational foundation and background with science and its applications as the core and inspiration of the curriculum for those whose broad intention it is to enter industry without reference to any particular occupation within it. It came to the very definite conclusion that the schools of this second 